\title{
Epidermolysis bullosa simplex due to BP230 deficiency
}

INSERM

\section{Source}

INSERM. (1999). Orphanet: an online rare disease and orphan drug data base. Epidermolysis bullosa simplex due to BP230 deficiency. ORPHA:412181

Epidermolysis bullosa simplex due to BP230 deficiency is a rare, hereditary, basal epidermolysis bullosa simplex characterized by mild, predominantly acral, trauma-induced skin frag ility, resulting in blisters. Blisters mostly affect the feet, including the dorsal side, and are often several centimetres big. 